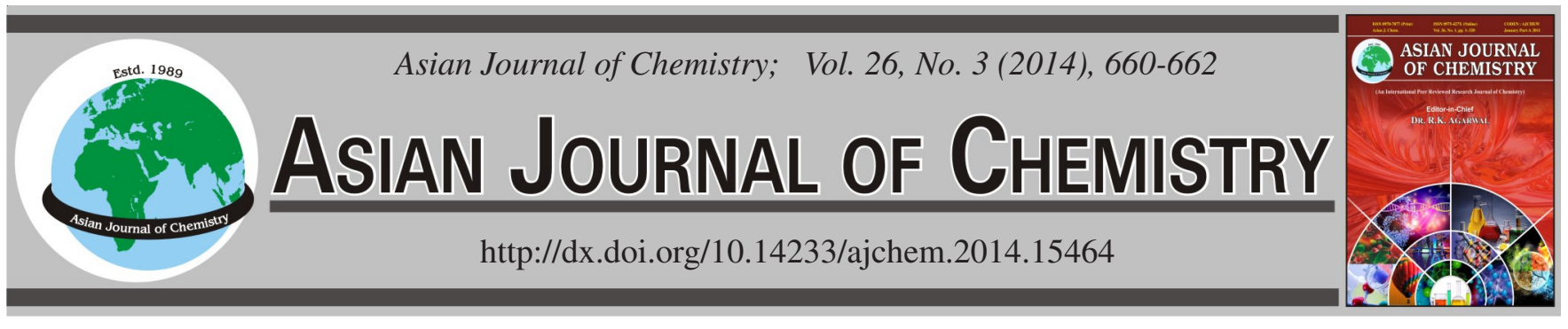

\title{
Morphology and Properties of Poly $(L$-lactic acid) Film Improved by Flexible Poly(butyl acrylate-co-methyl methacrylate)
}

\author{
Guo-Quan Zhu, Fa-Gang Wang ${ }^{*}$, Qiao-Chun Gao, Ke-Jing Xu and Yu-Ying LiU
}

School of Materials Science and Engineering, Shandong University of Technology, Zibo 255049, P.R. China

*Corresponding author: E-mail: fagangwang@126.com

\begin{abstract}
A series of poly(L-lactic acid) (PLLA)/poly(butyl acrylate-co-methyl methacrylate) (P(BA-co-MMA)) blend films were prepared by casting the polymer blend solution in chloroform. Surface morphologies of the PLLA/P(BA-co-MMA) blend films were investigated by scanning electron microscopy. Thermal and mechanical properties of PLLA/P(BA-co-MMA) blend films were studied by differential scanning calorimetry and tensile tests. The results revealed that the introduction of $\mathrm{P}(\mathrm{BA}-\mathrm{co}$-MMA) could strongly affect the properties of the $\operatorname{poly}(L$-lactic acid $)$ films.
\end{abstract}

Keywords: Poly( $L$-lactic acid), P(BA-co-MMA), Blend film, Morphology.

\section{INTRODUCTION}

Recently, poly(L-lactic acid) (PLLA) has received great attention in the research of alternative biodegradable polymer ${ }^{1-6}$. $\operatorname{Poly}(L$-lactic acid $)$ is a linear aliphatic thermoplastic polyester, produced from renewable resources ${ }^{5}$. Poly ( $L$-lactic acids) are prepared by ring-opening polymerization of lactides and the lactic acid monomers ${ }^{6}$. Usually, commercial poly(lactic acids) are copolymers of poly $(L$-lactic acid) (PLLA) and $\operatorname{poly}(D, L-$ lactic acid) (PDLLA), which are prepared from $L$-lactides and $D, L$-lactides, respectively ${ }^{1}$. To date, PLLA resins have mostly been used for biomedical applications such as drug delivery systems $^{7}$, surgical sutures ${ }^{8}$ and bone fixtures ${ }^{9}$. Due to the better biological degradation behavior, PLLA is expected to be a replacement material for conventional plastics such as PE, PVC and PET. These materials are practically used as packing materials (e.g., films, membranes) or foaming materials (e.g., containers $)^{10}$. Also, PLLA film is usually used as wound dressing (i.e., artificial skin $)^{11}$. However, the low deformation at break and quite elevated price of PLLA limit its applications ${ }^{1}$.

Nowadays, considerable efforts have been made to promote the properties of PLLA in order to compete with the low-cost and flexible commodity polymers. These attempts were carried out both by modifying PLLA with biocompatible plasticizers and by blending PLLA with other biopolymers ${ }^{1}$. Blends of PLLA with various non-biodegradable polymers have been investigated $^{12}$. Biodegradable blends of PLLA with other aliphatic polyesters such as poly $(\varepsilon \text {-caprolactone })^{13}$, poly(butylene succinate $)^{14}$ and poly(hydroxy butyrate) $)^{15}$ were also reported.
As known, the PLLA film holds poor flexibility ${ }^{16}$, while the synthetic polymer $\mathrm{P}$ (BA-co-MMA) (mole ratio of butyl acrylate to methyl methacrylate is 3:1) shows good flexibility ${ }^{17}$, the introduction of the synthetic P(BA-co-MMA) could improve the properties of PLLA film. However, to the best of our knowledge, no experimental work has been reported on the properties of PLLA/P(BA-co-MMA) blend film so far. In the present study, PLLA/P(BA-co-MMA) blend films were prepared by casting the polymer blend solution in chloroform. Surface morphologies of the PLLA/P(BA-co-MMA) blend films were investigated by SEM. Thermal and mechanical properties of PLLA/P(BA-co-MMA) blend films were studied by DSC and tensile tests. It was displayed that the introduction of $\mathrm{P}$ (BA-co-MMA) could exert great effects on the properties of PLLA films.

\section{EXPERIMENTAL}

The poly (L-lactic acid) (PLLA) $\left(\mathrm{M}_{\mathrm{w}}=80000\right)$ was purchased from Jinan Daigang Biomaterial Co. Ltd. (China). Poly(butyl acrylate-co-methyl methacrylate $)\left(\mathrm{M}_{\mathrm{w}}=40000\right.$, mole ratio of BA to MMA is 3:1) was purchased from Shandong Shituo Chemical Co. Ltd. (China). Chloroform was of analytical grade and used without further purification.

Preparation of PLLA/P(BA-co-MMA) blend film: The polymer blend films were prepared by casting a $30 \mathrm{wt} \%$ polymer blend solution in chloroform onto clean glass plates and drying them under vacuum at $50{ }^{\circ} \mathrm{C}$. It is also found that, when $\mathrm{P}(\mathrm{BA}-\mathrm{co}-\mathrm{MMA})$ mole content in polymer blend is over $12 \%$, the polymer blend can not form an continuous film. 
Test method: Scanning electron microscopic investigation was carried out using a scanning electron microscope (Sirin 200, FEI, Holland). Gold was sputtered on the samples in vacuum. Acceleration voltage was $5 \mathrm{kV}$ and photographs of the surface of the polymer blend films were taken. DSC measurements were made on a DSC Q100 (TA, USA) differential scanning calorimeter, the temperature calibrated with indium in nitrogen atmosphere. About $8 \mathrm{mg}$ sample was weighted very accurately. The temperature was controlled within the range between 0 and $250{ }^{\circ} \mathrm{C}$, the heating rate was $15^{\circ} \mathrm{C} / \mathrm{min}$. Tensile tests were carried out with an Instron 4468 machine (Digital Instruments Inc., USA). The crosshead speed was set to $150 \mathrm{~mm} / \mathrm{min}$. For each data point, five samples were tested and the average value was taken.

\section{RESULTS AND DISCUSSION}

The morphologies of PLLA/P(BA-co-MMA) blend film surface were studied by SEM technique. Fig. 1 indicates the surface morphologies of PLLA/P(BA-co-MMA) blend films with various $\mathrm{P}(\mathrm{BA}-\mathrm{co}-\mathrm{MMA})$ mole content: (a) 0 (b) 6 and (c) $12 \%$. As can be seen from Fig. 1, the introduction of P(BAco-MMA) changed the surface morphologies of the polymer
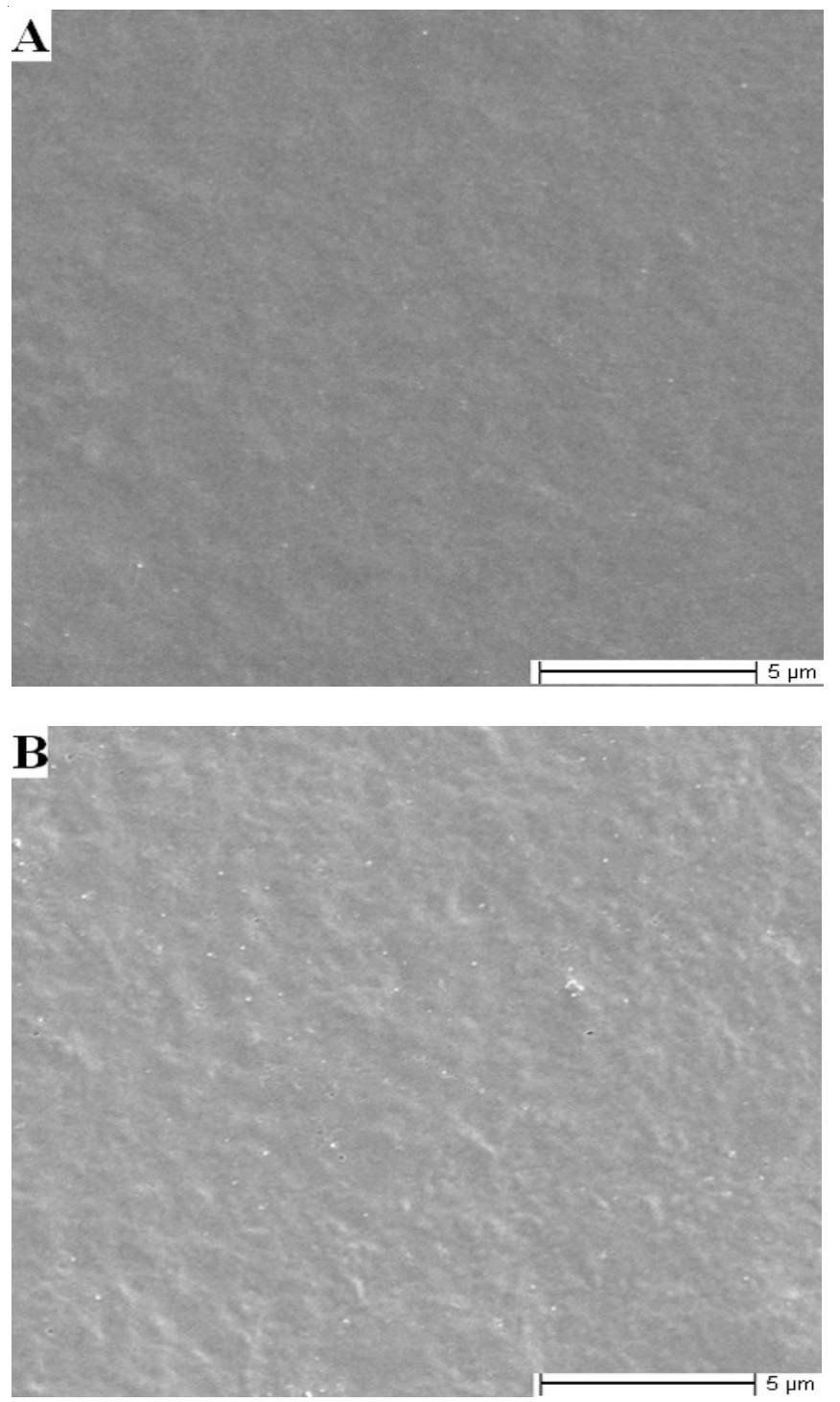

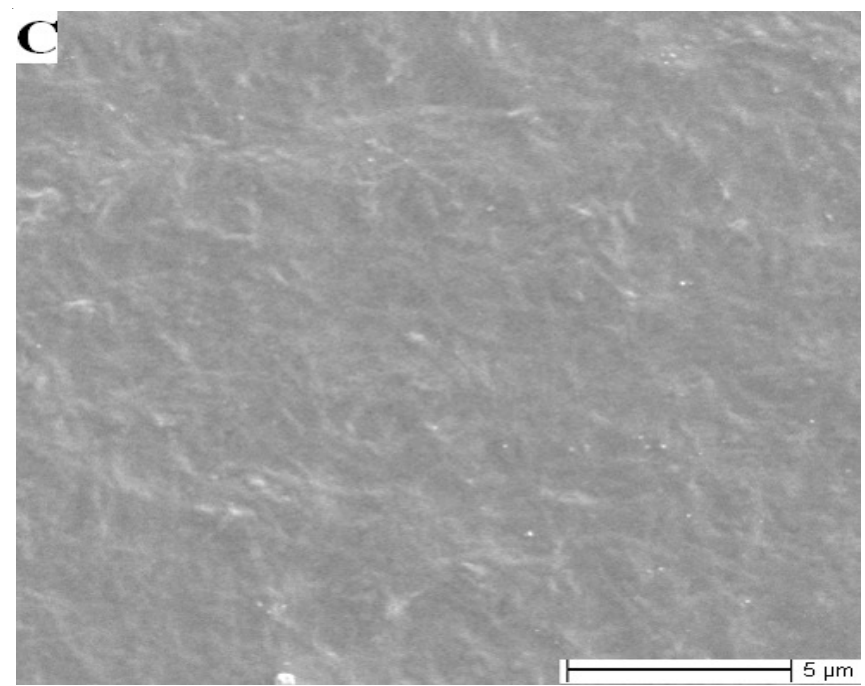

Fig. 1. SEM photographs of PLLA/P(BA-co-MMA) blend film surface with various $\mathrm{P}(\mathrm{BA}-\mathrm{co}-\mathrm{MMA})$ mole content: (a) 0 (b) 6 and (c) $12 \%$

blend films. The surface morphologies of PLLA films tend to become more rougher and appear a little phase-separation with the introduction of the $\mathrm{P}(\mathrm{BA}-$-co-MMA). As noted, with the increase of the $\mathrm{P}$ (BA-co-MMA) content in the polymer blend, on the one hand, PLLA chains and P(BA-co-MMA) segments could exert interaction through entanglement; on the other hand, the self-aggregating action could occur between the $\mathrm{P}$ (BA-co-MMA) segments. This phenomenon shows that the change of the surface morphologies of PLLA films could be attributed to the introduction of P(BA-co-MMA) segments.

DSC analysis: Fig. 2 presents the DSC curves of PLLA/ $\mathrm{P}(\mathrm{BA}-$-co-MMA) blends with various $\mathrm{P}(\mathrm{BA}-\mathrm{co}$-MMA) mole content: (a) 0, (b) 6 and (c) $12 \%$. The corresponding data are listed in Table-1. As seen from Fig. 2 and Table-1, the melting temperature of PLLA segments in the polymer blends decreased with the increase of $\mathrm{P}(\mathrm{BA}-\mathrm{co}-\mathrm{MMA})$ mole content. The relatively rigid PLLA segments and the flexible P(BA-co-MMA) chains could interact by entanglement, indicating that the decrease of the melting temperature of PLLA segments in polymer blends was related with the introduction of the flexible P(BA-co-MMA) chains.

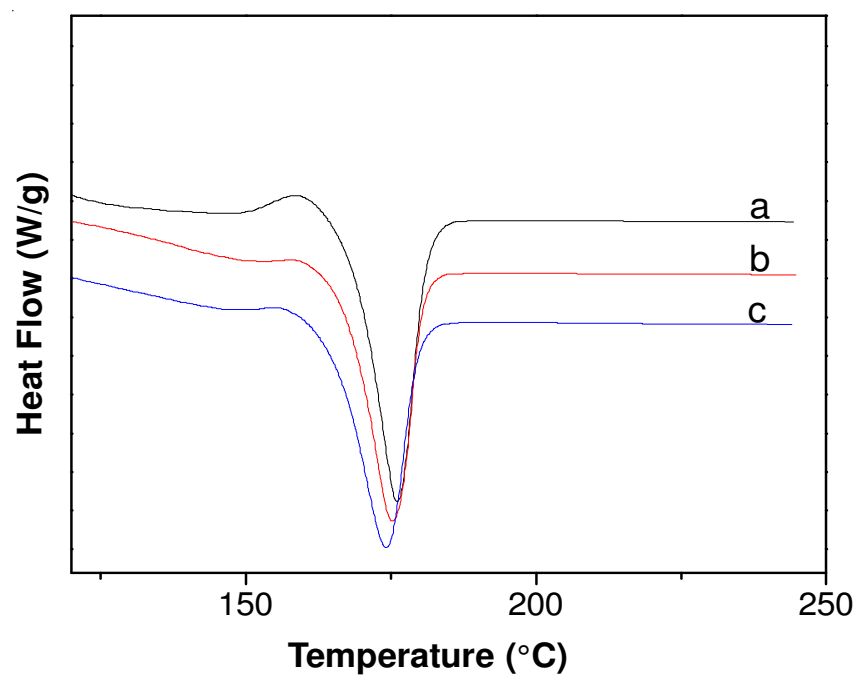

Fig. 2. DSC curves of PLLA/P(BA-co-MMA) blends with various P(BAco-MMA) mole content: (a) 0 (b) 6 and (c) $12 \%$ 
Tensile tests: Fig. 3 reveals the relationship between the tensile strength of PLLA/P(BA-co-MMA) blend film and the $\mathrm{P}$ (BA-co-MMA) mole content. As is shown in Fig. 3, the tensile strength of the PLLA/P(BA-co-MMA) blend film decreased with increasing the $\mathrm{P}(\mathrm{BA}-$ co-MMA) mole content. As already noted, the synthetic $\mathrm{P}(\mathrm{BA}-\mathrm{co}-\mathrm{MMA})$ (mole ratio of BA to MMA is 3:1) is flexible and the flexible P(BA-coMMA) segments could interact with PLLA chains through entanglement, suggesting that the decrease of tensile strength of the polymer blend film was connected with the introduction of the $\mathrm{P}(\mathrm{BA}-\mathrm{co}-\mathrm{MMA})$ segments. In the blend system, under evaluated $\mathrm{P}(\mathrm{BA}-$ co-MMA) content, the higher the $\mathrm{P}(\mathrm{BA}-\mathrm{co}-$ MMA) content, the lower the tensile strength of the polymer blend film.

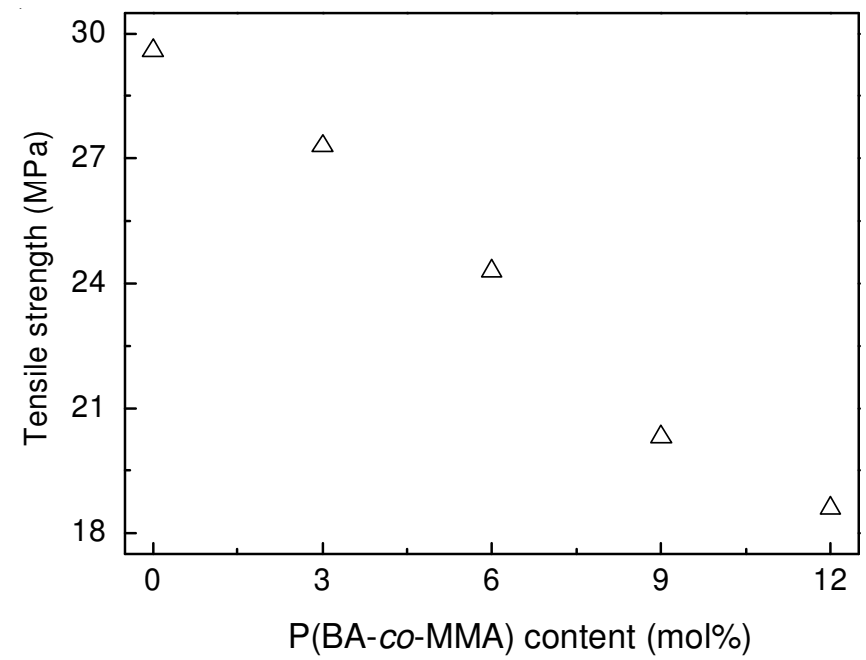

Fig. 3. Relationship between the tensile strength of PLLA/P(BA-co-MMA) blend film and P(BA-co-MMA) mole content

Fig. 4 exhibits the relationship between the elongation at break of the PLLA/P(BA-co-MMA) blend film and the P(BAco-MMA) mole content. As shown in Fig. 4, the elongation at break of the polymer blend film increased with the increase of the P(BA-co-MMA) mole content. As noted, the PLLA holds brittle property, while the synthetic $\mathrm{P}(\mathrm{BA}-\mathrm{co}-\mathrm{MMA})$ is flexible, indicating that the introduction of the flexible $\mathrm{P}(\mathrm{BA}-\mathrm{co}-\mathrm{MMA})$

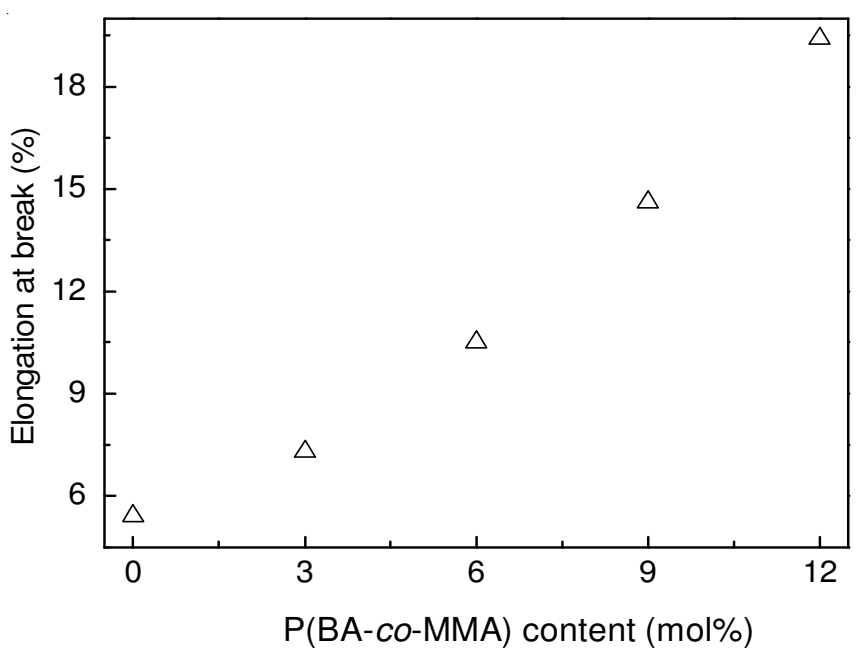

Fig. 4. Relationship between the elongation at break of PLLA/P(BA-coMMA) blend film and P(BA-co-MMA) mole content segments could promote the elongation at break of the polymer blend film by entanglement. In this blend system, under evaluated $\mathrm{P}(\mathrm{BA}-\mathrm{co}$-MMA) content, the higher the $\mathrm{P}(\mathrm{BA}-$ co-MMA) content, the higher the elongation at break of the polymer blend film.

\section{TABLE-1}

MELTING TEMPERATURE OF PLLA SEGMENTS IN POLYMER BLENDS WITH VARIOUS P(BA-co-MMA) MOLE CONTENT

\begin{tabular}{cc}
\hline P(BA-co-MMA) content $(\mathrm{mol} \%)$ & Melting temperature $\left({ }^{\circ} \mathrm{C}\right)$ \\
\hline 0 & 176.5 \\
6 & 175.3 \\
12 & 174.2 \\
\hline
\end{tabular}

\section{Conclusion}

A series of PLLA/P(BA-co-MMA) blend films with various $\mathrm{P}$ (BA-co-MMA) mole content were prepared by the solution casting method. SEM photographs indicated that the introduction of $\mathrm{P}(\mathrm{BA}-\mathrm{co}$-MMA) chains changed the surface morphologies of the polymer blend films. DSC data proved that the melting temperature of PLLA segments in the polymer blends decreased with the introduction of the $\mathrm{P}(\mathrm{BA}-\mathrm{co}-\mathrm{MMA})$ chains. Tensile tests verified that the introduction of the $\mathrm{P}(\mathrm{BA}-$ co-MMA) segments decreased the tensile strength of the polymer blend film but increased its elongation at break.

\section{ACKNOWLEDGEMENTS}

This work is supported by the Natural Science Foundation of Shandong Province (No. ZR2011EMM009).

\section{REFERENCES}

1. O. Martin and L. Averous, Polymer, 42, 6209 (2001).

2. D.W. Grijpma and A.J. Pennings, J. Macromol. Chem. Phys., 195, 1649 (1994).

3. G. Perego, G.D. Cella and C. Bastioli, J. Appl. Polym. Sci., 59, 37 (1996).

4. R.G. Sinclair, J. Macromol. Sci. A, 33, 585 (1996).

5. H. Tsuji and Y. Ikada, J. Appl. Polym. Sci., 67, 405 (1998).

6. J. Lunt, Polym. Degrad. Stab., 59, 145 (1998).

7. M. Vert, G. Schwaccch and J. Coudane, J. Macromol. Sci. A, 32, 787 (1995).

8. L. Fambri, A. Pegoretti, R. Fenner, S.D. Incardona and C. Migliaresi, Polymer, 38, 79 (1997).

9. J.E. Bergsma, R.R.M. Bos, F.R. Rozema, W.D. Jong and G. Boering, J. Mater. Sci. Mater. Med., 7, 1 (1996).

10. T. Komatsuka, A. Kusakabe and K. Nagai, Desalination, 234, 212 (2008).

11. C.C. Chen, J.Y. Chueh, H. Tseng, H.M. Huang and S.Y. Lee, Biomaterials, 24, 1167 (2003).

12. A.J. Nijenhuis, E. Colstee, D.W. Grijpma and A.J. Pennings, Polymer, 37, 5849 (1996).

13. L. Wang, W. Ma, R.A. Gross and S.P. Mccarthy, Polym. Degrad. Stab., 59, 161 (1998).

14. X. Liu, M. Dever, N. Fair and R.S. Benson, J. Environ. Polym. Degrad., 5, 225 (1997).

15. Y. Koyama and Y. Doi, Polymer, 38, 1589 (1997).

16. T.Y. Liu, W.C. Lin, M.C. Yang and S.Y. Chen, Polymer, 46, 12586 (2005).

17. G.Q. Zhu, G.C. Li and P. Wang, Polym.-Plast. Technol. Eng., 50, 1470 (2011). 